\title{
Attitude of Trans-Baikal State University Students to Conditions of Education in Electronic Environment during Coronavirus Period
}

\author{
Kokhan S.T. ${ }^{1,}$ Grabovskaya Ya.I. ${ }^{1}$, Nadeina L.V. ${ }^{2}$ \\ ${ }^{1}$ Regional Center for Inclusive Education, Trans-Baikal State University, Chita, Russia \\ ${ }^{2}$ Division for Foreign Languages, School of Core Engineering Education, National Research Tomsk Polytechnic \\ University, Tomsk, Russia \\ *Corresponding author.Email: ispsmed@mail.ru
}

\begin{abstract}
This article covers a number of problems and the effectiveness of the implementation of distance education at Trans-Baikal State University. The advantages and disadvantages of distance education at the university, indicated by the respondents who took part in the anonymous survey, are revealed. The article concludes that distance education in the context of the coronavirus was the only way to continue the educational process at the university. But the existing problems of the technical and economic plan were not a priority for students living in remote areas of Trans-Baikal Territory, since the technical connection for the implementation of the educational process was extremely low. When designing further optimal technical and software solutions for each educational program, it is necessary for the university administration to take into account the proposals of student youth to ensure the conditions for the implementation of the pedagogical principles of work and the technical capabilities of the available online technologies and equipment. The solution of these problems will make it possible to solve a number of problems related to ensuring the advantages of telecommunication forms of education in higher educational institutions.
\end{abstract}

Keywords: online learning, the Internet, distance education, student, university

\section{INTRODUCTION}

A global challenge to the modern education system was the total transition to distance education in all educational institutions, including universities [1]. This format of teaching higher school students revealed both positive and negative feedback on the proposed forms of interaction with teachers during a virus pandemic and isolation.

According to Reimers and Schleicher [2], the role of university teachers is essential to the success of the distance learning experience, as online learning for students becomes dominant during a pandemic.

The urgent transition to an electronic educational environment revealed a number of problems that faced not only students, but university teachers. Given the traditional full-time education in universities, the teachers were not ready for an urgent reorientation of their methodological recommendations of lectures and practical classes. Digitizing teaching materials requires a certain amount of time and the availability of appropriate computer technology, as well as information literacy of university teachers [3] (Bordonskaya et al., 2020). Providing access to the Internet is also an important problem. Hidson et al. [4] identifies e-learning opportunities for administrators and university teachers, considering video as part of pedagogical self-education and continuous professional development.

Michalski [5] reports on the prospects for diverse interaction in e-learning reflecting the dynamic link between individual, collegial, organizational and institutional levels of learning.

Depending on the possibilities, the administration of universities in different countries was forced to use a variety of forms of delivering educational materials in a distance format to their students. For example in Bulgaria, the TV channels BTV and On Air provided their airtime, and the university teachers acted as presenters. The training was organized not only for students, but also for everyone, including other teachers, parents and experts [6]. Mongolian university teachers used the same distance approaches in the educational process. Television lessons were the most common and widely used teaching method for all Mongolian students [7].

According to Blokhovtseva [8], distance learning (DL) is a combination of technologies that allow students to receive the entire volume of the studied information, dialogue communication between the student and the university teacher in the learning process with an emphasis on the student's independent work not only for mastering the studied material after classes, but also in the learning 
process itself. DL involves the use of such online technologies as the Internet, e-mail and computer telecommunications.

As in most countries in Russia attempts to reduce the spread and development of the new coronavirus disease (COVID-19) were primarily based on restrictive measures, including avoiding social interactions, as well as educational activities $[9,10]$. Education was forced to switch to a distance model. That is why a new form of education has appeared in pedagogical and student collectives - education in an electronic environment.

According to the World Economic Forum (WEF), among the 75 most developed countries, Russia takes only 71-st place in terms of access to and use of new educational technologies. Online education accounts for no more than $15 \%$ of the educational services market. The lack of practice of using online teaching methods and materials that could help the student independently, without attending classes, study the subject, is one of the important reasons for the rather low rates of implementation of distance learning technologies.

At Trans-Baikal State University (TBSU), the transition of teaching students using distance learning technologies as the main form of the educational process began on March 20, 2020. At the university before the pandemic distance learning technologies were used in exceptional cases for extramural students and an inclusive form for disabled persons in a wheelchair.

From 1 till 8 of June in 2020, the staff of the Department of Sociology of TBSU was conducting an anonymous survey of university students.

The aim of the study is to identify the level of student satisfaction with the organization of distance learning during the spread of COVID-19.

Research tasks:

- to identify the positive and negative experience of university students in the transition to a distance learning format;

- to determine the most popular practice of organizing distance learning among students.

\section{RESEARCH METHODOLOGY}

To solve the set tasks the content and internal structure of the survey in the form of a questionnaire were thought out. The student survey was carried out using the Google Forms system.

It was continuous sampling. A total of 2125 respondents took part in the study, which is $15 \%$ of the total number of university students. $28.9 \%$ of them were boys, and $71.1 \%$ were girls.

The survey was conducted among university students of all forms and levels of training. $78 \%$ of respondents were full-time students, and $22 \%$ were extramural students.

The age of the respondents was $25.9 \pm 6.7$.

The results were processed using Microsoft Excel and Google Sheets.

\section{RESULTS OF THE STUDY}

Analysis of the data obtained showed that students received information about the transition to distance learning from various sources, mainly from the curators of the groups and through the university website.

The students noted that, in general, assistance was organized for them by the university staff in the transition to distance learning using various mechanisms. However, $20.7 \%$ of the respondents said they did not have such assistance. Only $6.5 \%$ of the respondents took part in training seminars on working remotely. The most popular resources were the university's electronic information and educational environment (EIEE) and personal e-mail. These resources were noted by respondents as the main ones in distance learning. Social networks, including messengers, have also become convenient resources for students to communicate with university teachers in the context of distance learning.

During the study students were asked to assess the degree of ease of use of the university's information resources. In general, the students noted that the EIEE portal and the university website are quite convenient to use (average score of 4 points), and a significant part of the students do not use the scientific library site; they prefer online platforms, which causes certain difficulties in mastering the subject material presented by the university teacher.

Under these conditions, university students used laptops, personal computers and mobile phones for distance learning. The respondents noted that they used the phone in the absence of other means

The percentage of students' adaptation to the new conditions of distance learning is presented in figure 1: $39.1 \%$ of respondents indicated difficulties in adaptation; $19.2 \%$ of respondents did not manage to adapt to the new learning conditions. Only $19 \%$ of respondents have fully mastered the conditions of distance learning.

$40 \%$ of respondents said that they were not comfortable and difficult to study remotely. $51.5 \%$ of the respondents noted that, in general, it was convenient for them to study remotely, however, $32.9 \%$ of them noted that this form of training caused them certain difficulties.

$39.6 \%$ of respondents quickly mastered the electronic information and educational environment of the university, $24 \%$ independently sorted out this platform, but it took them time. $22.2 \%$ of respondents have not yet fully mastered this resource.

The absolute majority of respondents $(68.2 \%)$ noted that their level of training had increased or not increased significantly (18.2 per cent) when they switched to a new training format.

Intermediate certification in the current semester does not cause alarm only $25.5 \%$ of respondents, because they believe that the remote format of education in no way will affect their certification. Thirty-two percent of the respondents admitted that although they would give up the session on time, they would still have knowledge gaps. $32.9 \%$ of respondents believe that it is because of the 
transition to a remote form of training that they will not be fully certified.

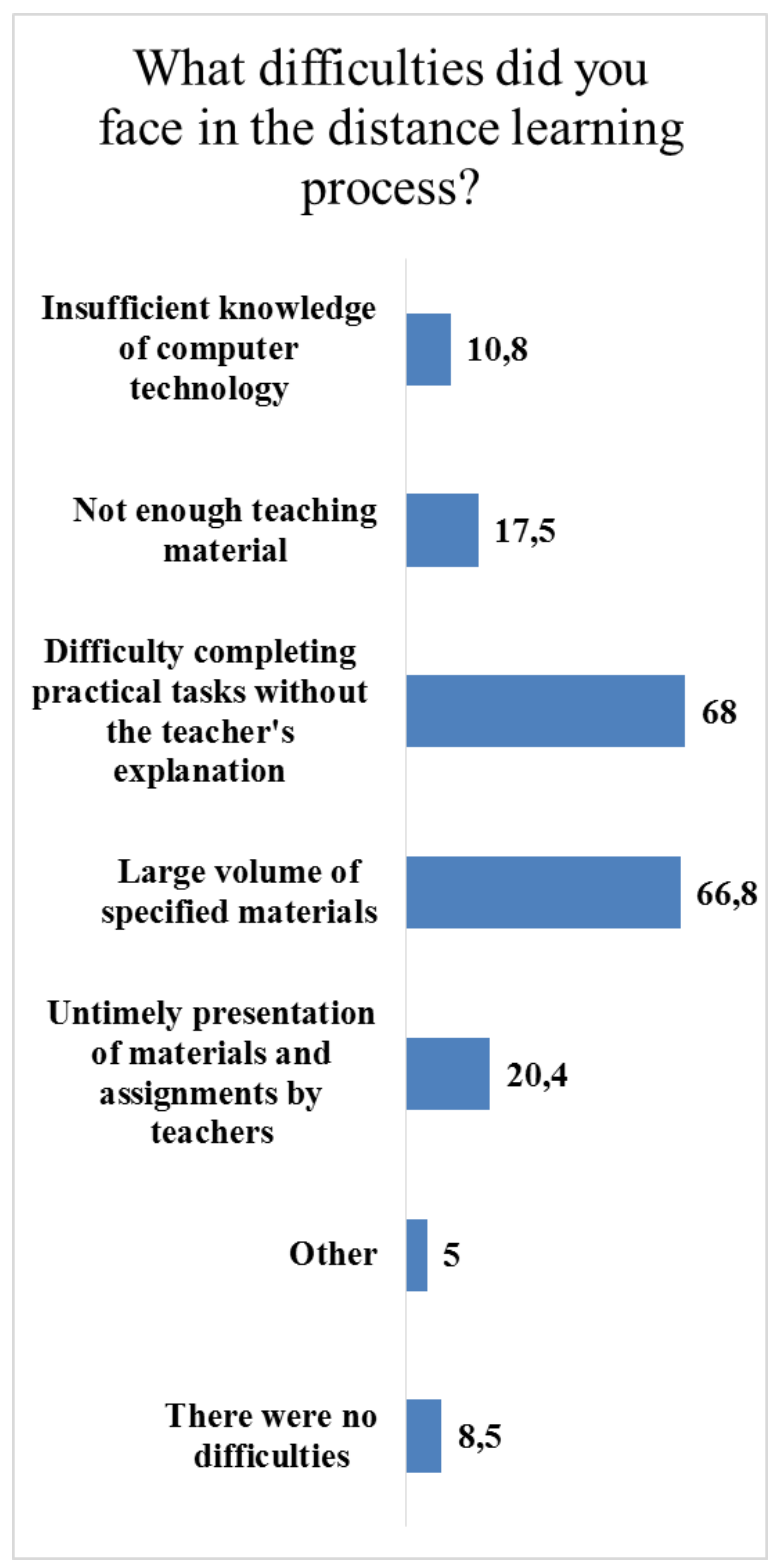

Figure 1 What difficulties did you face in the distance learning process?

* "Other" option: poor connection during video conferencing; Bad Internet; there is no connection with the teacher in the personal account; there was no connection with the teacher when completing assignments; the specialty is of a practical nature, etc.

On the whole, the students' assessment of the teachers' work is rather positive. $26.1 \%$ of the respondents rated the work "excellent", they noted that everything was clear and interesting; $20.2 \%$ of the respondents were generally satisfied with the quality of the work of the teaching staff, but would like to receive more additional materials on the topics studied; $32.1 \%$ of respondents did not understand all the material; $12.9 \%$ of respondents stated that the work was poorly organized, and the material was complex and not understandable. And as for $8.7 \%$ of respondents it should be noted that it was difficult for them to answer this question.

Students of the university were quite critical of the assessment of their own level of study material in the conditions of distance learning: $36.1 \%$ rated it as quite high, $31.8 \%$ - as satisfactory.

The main difficulties faced by students in distance learning are "the difficulty of performing practical tasks without the teacher's explanation" (68\%) and "a large volume of materials being asked (66.8\%). 20.4\% of respondents complained about the late display of materials and assignments by the university's teachers. $17.5 \%$ noted insufficient amount of educational material. 10.8 percent of those surveyed indicated that difficulties had arisen because of their lack of computer technology. Students also noted that difficulties were often related to external factors, such as unstable Internet, as well as pointed to the specifics of the specialty they receive, which is practical and requires off-line classes in laboratories / classrooms.

As technical problems that respondents encountered in the process of distance learning (figure 2), were identified: poor Internet speed $(45 \%)$, the need to have constant access to the network (41.1\%). 23.9\% of respondents noticed technical interruptions in the process of reproduction of materials. $11.2 \%$ of respondents noted that lectures and assignments were not always displayed. $27.5 \%$ of respondents said that there were no technical problems.

$50.1 \%$ of respondents have no claims on the technical support of distance learning at Trans-Baikal State University.

Most of all, students liked the individual pace of study (55.9\%), the possibility of receiving lecture materials, presentations $(38.3 \%)$, as well as self-learning (31.3\%). As for $25.5 \%$ of respondents, they were satisfied with the use of modern learning technologies and $21.5 \%$ of respondents were satisfied with the opportunity to test themselves. An increase in the amount of free time was noted by some students as the advantages of distance learning. Some students could not find the advantages of this format of study.

At present, respondents noted the value of learning in a comfortable and familiar environment $(45.9 \%)$, flexibility of the learning process $(43.9 \%)$, the ability to combine study with work $(38.7 \%)$ as the most important advantages of distance learning. $22.3 \%$ of respondents did not find the benefits of distance learning.

Despite these advantages of distance learning and a rather positive assessment of the organization of distance learning at Trans-Baikal State University, $71.2 \%$ of respondents would not like to continue their education in this format in the future. 


\section{What technical problems did you face in the distance learning process? (multiple answers)}

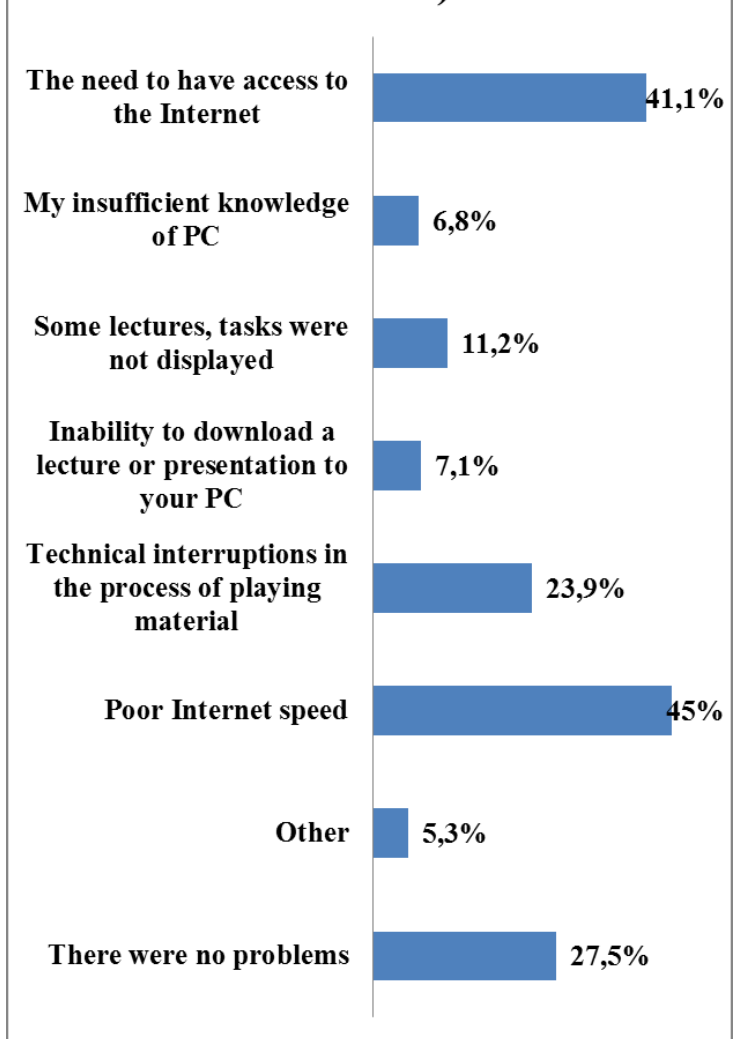

Figure 2 What technical problems did you face in the distance learning process?

* Option "other": interruption in the work of the website and personal account; no PC; 1 computer for the whole family; there is no way to install the necessary programs; regular blackouts; the teacher sent information in PDF files, etc.

\section{DISCUSSION}

Analyzing the opinion of the students of Trans-Baikal State University about distance learning proposed during the pandemic, it is necessary to recognize that for Russian universities, including TBSU, it is a priority to study offline. The main advantages of full-time education over distance learning are that the presence of communication with teachers during classes, solving situational problems in full-time education is the key to the success of education at the university.

According to Vayndorf-Sysoeva [11], for the effective organization of the educational process at the university it is necessary to understand the essence of the pedagogical potential of modern digital education in the context of a virus pandemic, which boils down to the orientation of teachers towards innovation, open education, and an individual approach to online learning. Thus, we can confidently assert that the urgently come period in the development of education is focused not only on the educational needs and needs of students, but also on new ways and methods of interaction with the introduction of various online technologies.

Teachers and students of universities, of course, will continue to seek flexible ways to address the learning disruption caused by a pandemic along learning paths. The expansion of online learning in higher education will undoubtedly accelerate, since certain benefits from online learning mechanisms while continuing their educational services will be in demand and relevant.

\section{CONCLUSION}

Summarizing the opinions of students participating in the study to improve the quality of distance learning at TBSU, their wishes to university teachers were divided into three groups:

Group 1 - "positive attitude": wishes for health, patience, the earliest possible stabilization of the situation, prosperity for the university, wishes of a speedy return to the buildings of the university, hopes for a quick meeting with classmates and teachers were expressed. Students said that they really miss the offline meetings with teachers, they lack personal contact in teaching. A large quantity of respondents simply said "thanks" to their university teachers.

Group 2 - "negative assessments of the organization of distance learning". It is important to note that this category can be conditionally divided into two more:

- a negative attitude towards the work of the teaching staff of the university, in particular, complaints were made against teachers (lack of contact, poor quality of lectures, a large number of assignments, etc.);

- a negative attitude in general to the current situation (students talk about fatigue, psychological stress, which is difficult to cope with).

Group 3 - "recommendations": as proposals, students indicated the need to reduce the volume of assignments (including their even distribution (not on the night before classes), organize consultations before tests and exams, and increase the number of video lectures and seminars. Students expressed a wish for a more correct attitude (communication) to them by teachers, not to leave their messages and homework unanswered and be sure to take into account the circumstances in which students are now (no computer, no stable high-speed Internet, etc.).

This research is important for building comprehensible forms of online interaction between university teachers and students after the pandemic ends. Teaching 
methodologies will be explored and refined, including the effectiveness of available electronic tools and online platforms.

\section{ACKNOWLEDGMENT}

The article was prepared as a part of a scientific grant of the Council for Scientific and Innovative Activities of Trans-Baikal State University No. 294 ГР (2020) "Study of adaptation characteristics of students with disabilities".

\section{REFERENCES}

[1] T.S. Zener, A.V. Oshkina, Peculiar features of remote learning at the university under forced conditions // International Journal of Humanities and Natural Sciences, vol. 5-3 (44), 2020, pp.170-177, https://doi.org/10.24411/2500-1000-2020-10576

[2] Reimers Fernando M., Schleicher Andreas. (2020). A framework to guide an education response to the COVID-19 Pandemic of 2020 // OECD. - P. 40. URL: https://learningportal.iiep.unesco.org/en/library/aframework-to-guide-an-education-response-to-thecovid-19-pandemic-of-2020. (Access date: 20.09.2020).

[3] L. A. Bordonskaya, E.A.Igumnova, K.G.

Erdyneeva, G.N. Sleptsova, S.S. Serebryakova, The Study of the Integration State in the Education System in the Conditions of Open Educational Space. Lecture Notes in Networks and Systems, 131, 2020, pp. 871882. https://doi.org/10.1007/978-3-030-47415-7_94 URL: ttps://www.scopus.com/record/display.uri?eid=2s2.0-85085478859\&doi $=10.1007 \% 2$ f978-3-030-474157_94\&origin $=$ inward\&txGid=6231962678850d 148615 ed91cd35ad61 (Access date: 19.09.2020).

[4] E. Hidson, 'Video-Enhanced Lesson Observation as a Source of Multiple Modes of Data for School Leadership: A Videographic Approach', Management in Education, vol. 32, iss. 1, 2018, pp. 26-31, https://doi.org/10.1177\%2F0892020617748144

[5] M. P. Michalski, 'Symbolic Meanings and ELearning in the Workplace: The Case of an IntranetBased Training Tool', Management Learning, vol. 45, iss. 2, 2014, pp. 145-166,

<https://doi.org/10.1177\%2F1350507612468419>.

[6] D. S. Levterova-Gadgzalova, Intergenerational relations in an e-learning environment during the covid-19 pandemic // Intergenerational relations: modern discourse and strategic choices in psychological and pedagogical science and practice. 2020, pp. 21-25.

[7] K.I. Bikmaeva, Distance learning in Mongolia during the coronavirus pandemic in 2020 // Modern pedagogical education. 2020. No. 5, pp. 9-14.

[8] G. G. Blokhovtseva, Prospects for the development of distance learning / G. G. Blokhovtseva, T. L. Malikova, A. A. Simonenko // New science: strategy and vectors of development. 2016. No.118-3, pp. 89-92.

[9] G. Basilaia, \& D. Kvavadze, (2020). Transition to Online Education in Schools during a SARS-CoV-2 Coronavirus (COVID-19) Pandemic in Georgia. Pedagogical Research, 5(4), em0060. https://doi.org/10.29333/pr/7937

[10] E. J. Sintema, (2020). Effect of COVID-19 on the Performance of Grade 12 Students: Implications for STEM Education. Eurasia Journal of Mathematics, Science and Technology Education, 16(7), em1851. https://doi.org/10.29333/ejmste/7893

[11] M. Ye. Vayndorf-Sysoeva, Digital learning in the context of modern education: application practice: monograph / M. Ye. Vayndorf-Sysoeva, M. L. Subocheva; MSPU. - M.: Diona, 2020, 244 p. 